\title{
AVALIAÇÃO DE ÓLEOS ESSENCIAIS SOBRE O CRESCIMENTO IN VITRO DO FUNGO Colletotrichum gloeosporioides
}

\author{
Roberta Manhães Alves Machado \\ Licenciada em Química / Instituto Federal Fluminense / RJ \\ robertamalves@yahoo.com.br
}

\section{Vicente Mussi-Dias}

Doutor em Produção Vegetal / Universidade Estadual do Norte Fluminense Darcy Ribeiro / RJ

vimdias@yahoo.com.br

\section{Claudio Luiz Melo de Souza}

Doutor em Produção Vegetal / Institutos Superiores de Ensino do CENSA / RJ

veronicade@ig.com.br

\section{Luciana Belarmindo da Silva}

Doutora em Biociências e Biotecnologia / Instituto Federal Fluminense / RJ

lbelarmindo@yahoo.com.br

\section{Maria das Graças Machado Freire}

Doutora em Biologia Funcional e Molecular / Institutos Superiores de Ensino do CENSA / RJ

freire.mgm@gmail.com

Recebido: 15 de março de 2013. Revisado: 19 de março de 2013. Aceito: 20 de março de 2013. Publicado online: 26 de março de 2013.

\section{RESUMO}

Uma considerável parcela da produção agrícola mundial se perde, principalmente, devido às doenças na póscolheita causadas por microorganismos fitopatogênicos, dentre eles os fungos. A utilização de plantas, cujos componentes apresentam atividades fungicidas vem sendo pesquisadas visando o controle alternativo dessas doenças, visto que a sociedade tem buscado o consumo de produtos com o mínimo possível de agrotóxicos. O objetivo deste trabalho foi avaliar a ação fungitóxica de óleos essenciais de Andiroba, Bacuri, Bocaiúva, Buriti, Castanha do Brasil, Cabreúva, Castanha do Pará, Citronela, Coco babaçu, Copaíba, Eucalipto, Maracujá, Pequi, Pracaxi, Sapucaia e Tucumã sobre o crescimento micelial in vitro do fungo Colletotrichum gloeosporioides, agente causal da Antracnose na pós-colheita de mamão e de diversas outras culturas. Cada óleo foi incorporado ao meio de cultura e o crescimento micelial do fungo foi avaliado durante cinco dias. Os óleos de citronela e de eucalipto inibiram $100 \%$ o crescimento micelial do fungo nas dosagens de $13 \mu \mathrm{L} / \mathrm{mL}$ (v/v) e $1 \mathrm{mg} / \mathrm{mL}(\mathrm{p} / \mathrm{v})$. Os demais óleos testados apresentaram efeitos semelhantes aos do controle. Dessa forma, sugere-se que, os óleos essenciais estudados podem ser utilizados no desenvolvimento de métodos alternativos de controle da antracnose em frutos de mamão, com destaque para os óleos de citronela e eucalipto. O óleo de citronela apresentou maior atividade contra o crescimento micelial de Colletotrichum gloeosporioides in vitro e deve ser testado, in vivo, na confirmação e comparação de sua eficiência em relação a produtos convencionais utilizados no controle dessa doença.

Palavras-chave: Doenças pós-colheita, Mamão, Óleo essencial, Método alternativo de controle, Antracnose 


\section{ABSTRACT}

A considerable share of global agricultural production is lost, mainly due to post-harvest diseases caused by pathogenic microorganisms, including fungi. The use of plants whose components exhibit fungicidal activity has been researched alternative for the control of these diseases, since the society have find to consume products with the least amount of pesticides. The objective of this study was to evaluate the fungitoxic action Andiroba, Bacuri, Bocaiúva, Buriti, Castanha do Brasil, Cabreúva, Citronela, Coco Babaçu, Copaiba, Eucalyptus, Maracujá, Pequi, Pracaxi, Sapucaia, Tucumã essential oils on the mycelial growth on the fungus Colletotrichum gloeosporioides, causal agent of the post-harvest anthracnose of papaya and several other crops. Each oil was incorporated into the culture medium and mycelial growth was evaluated for five days. The citronela and eucalyptus oils, $100 \%$ inhibited the mycelial growth of the fungus in dosages of $13 \mathrm{~mL} / \mathrm{mL}(\mathrm{v} / \mathrm{v})$ and $1 \mathrm{mg} / \mathrm{mL}(\mathrm{w} / \mathrm{v})$, respectively. The other oils tested had similar effects to those of control. Thus, the studied of these essential oils can be used in the study of alternative methods for the control of anthracnose in papaya fruits, especially the oils of citronella and eucalyptus. The citronela oil showed higher efficiency against the mycelial growth of Colletotrichum gloeosporioides in vitro and should be tested in vivo to confirm and to compare their efficiency with conventional products used to control this disease.

Keywords: Post-harvest diseases, Papaya, essential oil, alternative control method, Anthracnose

\section{INTRODUÇAO}

Uma das questões prementes de nossos dias é o acelerado crescimento da população não condizente com a produção e o fornecimento de alimento, um desafio para a humanidade. Estima-se que a população humana poderá chegar a 9,1 bilhões em 2050 e o número de pessoas subnutridas no mundo em 2008 foi superior a 915 milhões (FAO, 2009a), o maior nas últimas quatro décadas. Em outubro de 2011 o número total da população do planeta atingiu 7 bilhões de pessoas colocando-nos sob condição de insegurança alimentar (OLIVEIRA, 2011).

A produção agrícola destinada à alimentação e produção de biocombustível deve crescer aproximadamente 70\% (FAO, 2009b) e, no caso da fruticultura, o Brasil tem se destacado como importante produtor, consumidor e exportador de frutas tropicais, expandindo o agronegócio e buscando adequação ao mercado consumidor (SILVEIRA et al, 2005). No entanto, o volume de exportação ainda é pequeno, principalmente devido às perdas estimadas em 10 milhões de $\mathrm{t} / \mathrm{ano}$, correspondendo a $30-40 \%$ da produção (BENATO, 1999).

Segundo Senhor et al (2009), apesar da rápida expansão da agricultura brasileira, alguns segmentos da cadeia produtiva são muito frágeis e pouco estudados, como é o caso da patologia pós-colheita. Cerca de $20 \%$ ou mais dos produtos colhidos são perdidos devido ao ataque de insetos-praga, nematóides e microorganismos fitopatogênicos. Os patógenos, principalmente, os quiescentes, têm causado danos consideráveis aos atacadistas, varejistas e principalmente aos importadores de frutos, por serem de difícil controle nos estágios de colheita, transporte, armazenamento e comercialização (MORANDIR, 2002).

Uma das importantes culturas de comercialização para o Brasil é o mamão, do qual o país é o principal produtor mundial com cerca de $1.898 .000 \mathrm{t}$ de frutos no ano de 2009 (FAO, 2009c). Nesta cultura, as doenças causadas por fungos constituem um fator limitante, principalmente para a exportação do mamão 
in natura. Nos frutos, os patógenos causam perdas de até $75 \%$ na fase de comercialização (ECKERT, 1993), o que desqualifica a fruta para venda e consumo. Dantas et al (2003) encontraram doenças fúngicas em $82,5 \%$ de frutos amostrados em central de abastecimento. A elevada incidência desse tipo de doença pode ser explicada pela sensibilidade da casca a penetração de patógenos (GAYET et al, 1995). Entretanto, todos os estágios da cultura são suscetíveis a uma ou mais doenças, e o êxito da produção dependerá exclusivamente da incidência das mesmas, o que, por sua vez, exige a adoção de medidas adequadas de controle (SILVEIRA et al, 2005; MARTINS; FARIAS, 2002).

Entre os principais agentes etiológicos das enfermidades dos frutos de mamão podem ser destacados os fungos Asperisporium caricae (Speg.) Maubl., Fusarium Link, Phoma caricae-papayae (Tarr.) Punith., Lasiodiplodia theobromae (Pat.) Griffon \& Maulb., Phomopsis caricae-papayae Petr. \& Cif., Rhizopus stolonifer (Ehrenb.) Vuill., Phytophthora palmivora (E. J. Butler) E. J. Butler, Pestalotia De not. e Colletotrichum gloeosporioides (Penz.) Penz. \& Sacc., (DANTAS et al, 2003), este último, causador da "Antracnose".

A doença se manifesta principalmente na fase de amadurecimento do fruto, durante o transporte, armazenamento e comercialização. Sintomas típicos se caracterizam por lesões deprimidas medindo até $5 \mathrm{~cm}$ de diâmetro, em torno das quais se forma um tecido aquoso. No centro deste formam-se pontuações alaranjadas que correspondem às massas de conídios produzidos pelo fungo (BONETT et al, 2010). As lesões podem coalescer, estendendo-se pela superfície do fruto ao mesmo tempo em que se aprofundam na polpa e ocasionam a podridão mole (FREIRE et al, 2003; MANICA, 1982).

A incidência de $C$. gloeosporioides é comum em diversas fruteiras tropicais, como manga, abacate e goiaba (BONETT et al, 2010). A infecção pode iniciar ainda na floração, permanecendo latente, ou seja, sem o aparecimento dos sintomas, até a colheita, por ocasião do amadurecimento do fruto. Esta e outras peculiaridades no ciclo das relações patógeno-hospedeiro, tornam a antracnose uma doença de difícil controle. Neste sentido, recomenda-se antes da fase de maturação, tratamento hidrotérmico associado a fungicidas e aplicação de ceras para garantir uma maior sobrevida ao fruto (AGROFIT, 2012).

O controle de doenças pós-colheita é um dos grandes desafios para minimizar as perdas, que até então, vem se baseando na estratégia de uso de fungicidas. Entretanto, com a crescente restrição ao uso de defensivos, devido aos problemas por toxidez dos compostos, desenvolvimento de resistência dos patógenos e os efeitos prejudiciais ao meio ambiente e à saúde humana tem-se estimulado o uso de métodos alternativos para controle de doenças pós-colheita (BASSETTO, 2006; STEVENS et al, 1991).

Bassetto (2006) aponta outras técnicas alternativas de controle às doenças pós-colheita, como o biocontrole, o tratamento térmico, as irradiações gama e UV-C, o uso de atmosfera modificada, a refrigeração e a utilização de compostos naturais. Estes últimos, extraídos de plantas com propriedades antibióticas, tem sido empregados na tentativa de reduzir o uso indiscriminado de defensivos agrícolas e mostram-se, muitas vezes, eficientes no controle de microorganismos patogênicos a plantas.

Os óleos essenciais são produtos voláteis do metabolismo secundário de plantas aromáticas, formados em células especiais e encontrados em folhas, flores, sementes, caules e raízes. A ISO (International Standard Organization) define óleos essenciais como os produtos obtidos de partes de plantas mediante destilação por arraste com vapor d'água, bem como os produtos obtidos por expressão dos pericarpos de frutos cítricos.

De forma geral, são misturas complexas de substâncias voláteis, lipofílicas, geralmente odoríferas e líquidas (SANTOS, 2004). Seus constituintes variam desde hidrocarbonetos terpênicos, alcoóis simples e terpênicos, aldeídos, cetonas, fenóis, ésteres, éteres, óxidos, peróxidos, furanos, ácidos orgânicos, lactonas e cumarinas, até compostos com enxofre. $\mathrm{Na}$ mistura, tais compostos apresentam-se em diferentes concentrações; normalmente, um deles é o composto majoritário, existindo outros em menores teores e alguns em baixíssimas quantidades (traços) (Simões et al, 2004). Quimicamente, a maioria dos óleos essenciais é constituída de derivados fenilpropanóides ou de terpenóides, preponderando esses últimos. Normalmente apresentam um composto majoritário (CARDOSO et al, 2001). 
Esses óleos são fontes de agentes biocidas, por isso vem sendo amplamente estudados na agricultura, principalmente por suas funções bactericida, fungicida e inseticida (CRAVEIRO; MACHADO, 1986; PRASHAR et al, 2003).

A atividade antifúngica dos óleos essenciais está associada aos seus componentes, mesmo não sendo muito conhecidos os mecanismos de ação. O potencial desses óleos essenciais se dá tanto por ação fungitóxica direta, inibindo o crescimento micelial e a germinação de esporos, quanto pela indução de fitoalexinas, metabólitos secundários produzidos pelas plantas em resposta a estresses físicos, químicos ou biológicos, que podem impedir a atividade de agentes patogênicos (STANGARLIN et al, 1999). Além disso, a utilização desses agentes apresenta duas vantagens adicionais: maior segurança às pessoas e ao meio ambiente e baixo risco para o desenvolvimento de resistência em microorganismos patogênicos, devido à mistura de componentes presentes nos óleos (MOURA, 2007).

Diante da tendência do mercado, intensifica-se a necessidade de métodos e produtos que substitua insumos poluentes, mantenha a qualidade dos alimentos, reduza os resíduos químicos nos frutos e aumente a segurança e a saúde do consumidor (PIATI et al, 2011).

Dentro deste contexto, objetivou-se neste trabalho avaliar a eficiência de óleos essenciais no controle do crescimento in vitro de Colletotrichum gloeosporioides, agente causal da Antracnose do mamão.

\section{MATERIAL E MÉTODOS}

\subsection{Obtenção e conservação do patógeno}

O fungo Colletotrichum gloeosporioides, cadastrado sob o código "IB 18/85", foi obtido da micoteca do Instituto Biológico/SP. Outros isolados foram provenientes de frutos de mamão comercializados no município de Campos dos Goytacazes, RJ, obtidos por isolamento direto em meio de cultura batata-dextroseágar (BDA) (DHINGRA; SINCLAIR, 1995), a partir de lesões características da doença.

Cada isolado foi conservado pelo método de Castellani (CASTELLANI, 1964), em frascos de vidro (tipo penicilina) e mantidos à temperatura ambiente. As colônias foram cultivadas em placas de petri contendo meio BDA com repicagens periódicas para serem utilizadas nos ensaios.

\subsection{Obtenção dos óleos essenciais}

Os óleos essenciais utilizados foram: Andiroba, Bacuri, Bocaiúva, Buriti, Castanha do Brasil, Cabreúva, Castanha do Pará, Citronela, Coco babaçu, Copaíba, Eucalipto, Maracujá, Pequi, Pracaxi, Sapucaia e Tucumã, adquiridos de J. dos Santos Ferrari (Químico responsável: Sérgio Ferrari).

\subsection{Avaliação da ação fungitóxica dos óleos essenciais in vitro}

O estudo dos efeitos dos óleos essenciais das diferentes espécies vegetais sobre o fungo foi realizado em dois ensaios distintos.

No primeiro deles, todos os óleos obtidos foram previamente testados a fim de pré-selecionar os mais eficientes para a etapa seguinte. Para tanto, foram usadas placas de petri de $9 \mathrm{~cm}$ de diâmetro, as quais foram adicionados cerca de $15 \mathrm{~mL}$ de meio BDA contendo $200 \mu \mathrm{L}$ do óleo essencial (adaptado de OLIVEIRA et al, 2008), além do tratamento controle.

No segundo ensaio, os óleos que apresentaram melhores resultados no ensaio anterior foram selecionados para dar sequência aos estudos, por meio de dose-resposta. Nesse caso, utilizaram-se como tratamentos o óleo bruto e as concentrações de 750,500 e $250 \mathrm{mg} / \mathrm{L}$ destes óleos, diluídas em solução aquosa de Tween 80 a $1 \%$ e adicionadas ao meio de cultura. Além do tratamento controle, sem os óleos, utilizou-se também um controle para a solução diluente. 
Em ambos os ensaios, após a solidificação do BDA, um disco de $1 \mathrm{~cm}$ de diâmetro da borda da cultura de C. gloeosporioides com 7 dias de crescimento, foi repicado para o centro de cada placa, as quais foram vedadas com filme de policloreto de vinila (PVC) e mantidas à temperatura ambiente. Todo o experimento foi realizado em triplicata.

A avaliação do crescimento micelial foi verificada diariamente, por meio de medições de dois eixos perpendiculares na face inferior das placas, até que as primeiras colônias atingissem a borda. Utilizou-se para isso uma régua milimetrada.

Os ensaios foram realizados no Laboratório de Química e Biomoléculas (Laquibio), dos Institutos Superiores de Ensino do CENSA (ISECENSA) em Campos dos Goytacazes, RJ.

\subsection{Análises estatísticas}

Os ensaios foram conduzidos segundo delineamento inteiramente casualizado com 3 repetições por tratamento. Os dados foram submetidos à análise da variância e comparação de médias pelo teste de Tukey $(\mathrm{P}<0,05)$. Quando necessário, os dados foram transformados pela raiz quadrada de $(x+0,5)$ para maior homogeneidade nas análises de variâncias e as médias finais foram apresentadas sem as transformações. As concentrações testadas foram submetidas à análise da variância para regressão linear e múltipla para obtenção das equações com melhor ajuste ao parâmetro estudado e, quando necessário, comparação das médias dos coeficientes angulares por meio do teste de Tukey $(\mathrm{P}<0,05)$ (PIMENTEL GOMES, 2000). As análises estatísticas foram calculadas com auxílio do programa SAEG, Sistema para Análises Estatísticas (SAEG, 2000).

\section{RESULTADOS E DISCUSSÃO}

A avaliação da ação fungitóxica de todos os óleos essenciais testados in vitro, contra $C$. gloeosporioides, foi comparada por meio de análise de regressão do halo de crescimento micelial (HCM) do fungo (Tabela 1). Evidenciou-se o efeito diferenciado na atividade microbiana dos óleos de copaíba, cabreúva, citronela e eucalipto, os quais apresentaram menor coeficiente angular, portanto menor crescimento micelial.

Tabela 1: Ação de óleos essenciais de diferentes espécies vegetais sobre o crescimento micelial (HCM) in vitro de Colletotrichum gloeosporioides durante um período de cinco dias

\begin{tabular}{lccc}
\multicolumn{1}{c}{ Tratamento } & HCM (cm) & Equação & $\mathbf{R}^{2}$ \\
\hline Controle & 4,95 & $\mathrm{y}=0,955 \mathrm{x}+0,025$ & $0,99^{*}$ \\
Tween 80 & 3,65 & $\mathrm{y}=0,675 \mathrm{x}+0,019$ & $0,98^{*}$ \\
Pequi & 5,00 & $\mathrm{y}=1,005 \mathrm{x}-0,025$ & $0,99^{*}$ \\
Bocaiúva & 4,80 & $\mathrm{y}=0,955 \mathrm{x}+0,035$ & $0,99^{*}$ \\
Castanha do Pará & 4,85 & $\mathrm{y}=0,955 \mathrm{x}+0,035$ & $0,99^{*}$ \\
Bacuri & 4,70 & $\mathrm{y}=0,925 \mathrm{x}+0,029$ & $0,99^{*}$ \\
Maracujá & 4,55 & $\mathrm{y}=0,915 \mathrm{x}-0,015$ & $0,99^{*}$ \\
Sapucaia & 4,60 & $\mathrm{y}=0,895 \mathrm{x}+0,055$ & $0,99^{*}$ \\
Castanha do Brasil & 4,60 & $\mathrm{y}=0,890 \mathrm{x}+0,210$ & $0,99^{*}$ \\
Tucumã & 4,25 & $\mathrm{y}=0,820 \mathrm{x}+0,240$ & $0,99^{*}$ \\
Pracaxi & 4,10 & $\mathrm{y}=0,775 \mathrm{x}+0,235$ & $0,99^{*}$ \\
Buriti & 4,10 & $\mathrm{y}=0,745 \mathrm{x}+0,425$ & $0,99^{*}$ \\
Andiroba & 3,95 & $\mathrm{y}=0,740 \mathrm{x}+0,140$ & $0,99^{*}$ \\
Coco babaçu & 3,80 & $\mathrm{y}=0,700 \mathrm{x}+0,140$ & $0,93^{*}$ \\
\hline Copaíba & 3,15 & $\mathrm{y}=0,555 \mathrm{x}+0,455$ & $0,96^{*}$ \\
Cabreúva & 2,40 & $\mathrm{y}=0,333 \mathrm{x}+0,741$ & $0,98^{*}$ \\
Citronela & 1,00 & Média $=1,00$ & - \\
Eucalipto & 1,00 & Média $=1,00$ & - \\
\hline $\mathrm{R}^{2}=0,99-0=$ coeficiente de determinação da reta; $*$ Análise da variância da regressão significativa, \\
segundo o Teste F $(\mathrm{P}<0,05)$. & & \\
\hline
\end{tabular}

Persp. online: biol. \& saúde, Campos dos Goytacazes, 8 (3), 64-75, 2013 
Estes quatro óleos essenciais extraídos de copaíba, cabreúva, citronela e eucalipto foram escolhidos para dar prosseguimento aos testes de atividade antifúngica. Os outros óleos testados apresentaram efeitos semelhantes ao das testemunhas, ou seja, não foram eficientes no controle do crescimento do fungo na dose aplicada. Doses mais concentradas desses óleos poderiam ser testadas em estudos futuros.

No segundo ensaio, a análise da variância para o parâmetro crescimento micelial de $C$. gloeosporioides apresentou efeito significativo a partir do $3^{\circ}$ dia de incubação do fungo $(\mathrm{P}<0,05)$, sendo evidenciada maior inibição do crescimento micelial no $5^{\circ}$ dia em relação aos controles: água destilada esterilizada ou Tween 80 (Figura 1). Com relação ao efeito total, que corresponde à média de todos os dias de avaliação, foi possível evidenciar os efeitos antifúngicos de dois óleos essenciais: óleo de citronela e óleo de eucalipto.

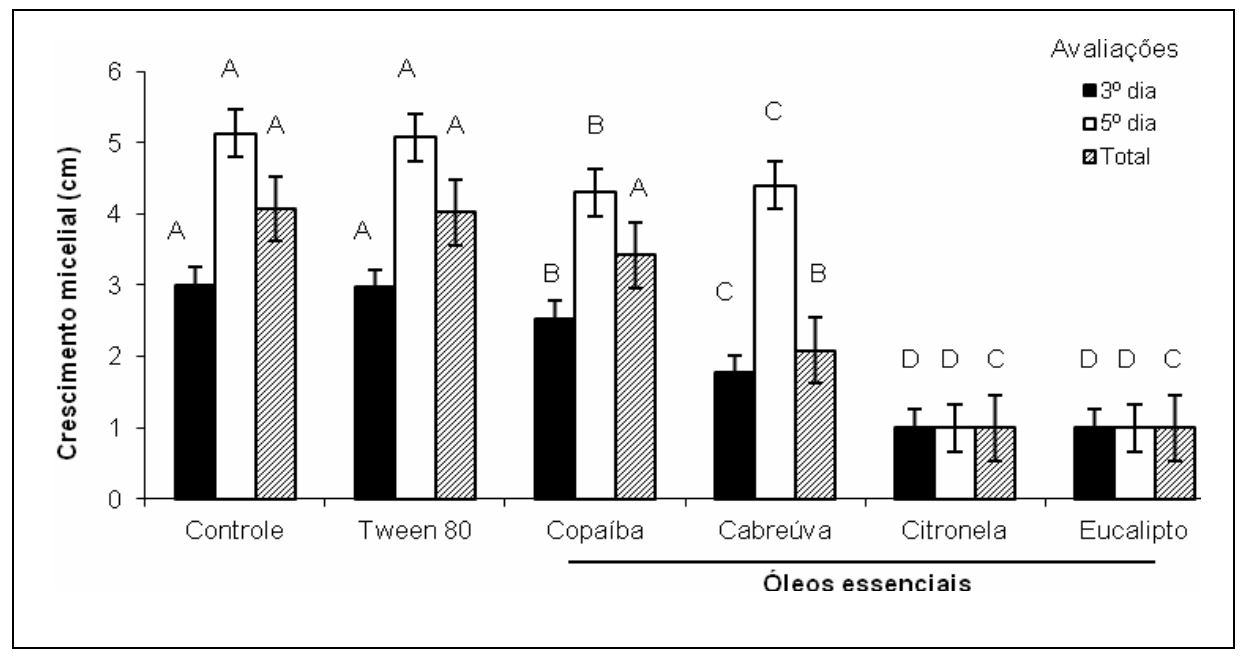

Figura 1: Crescimento micelial in vitro do fungo Colletotrichum gloeosporioides sob ação dos óleos essenciais durante cinco dias de incubação (Médias seguidas das mesmas letras não diferem entre si, segundo o teste de Tukey $(\mathrm{P}<0,05)$.

Os óleos de citronela e eucalipto apresentaram maior efeito inibitório no crescimento micelial de $C$. gloeosporioides (Figura 2), consequentemente, estes foram selecionados para estudos do efeito doseresposta.

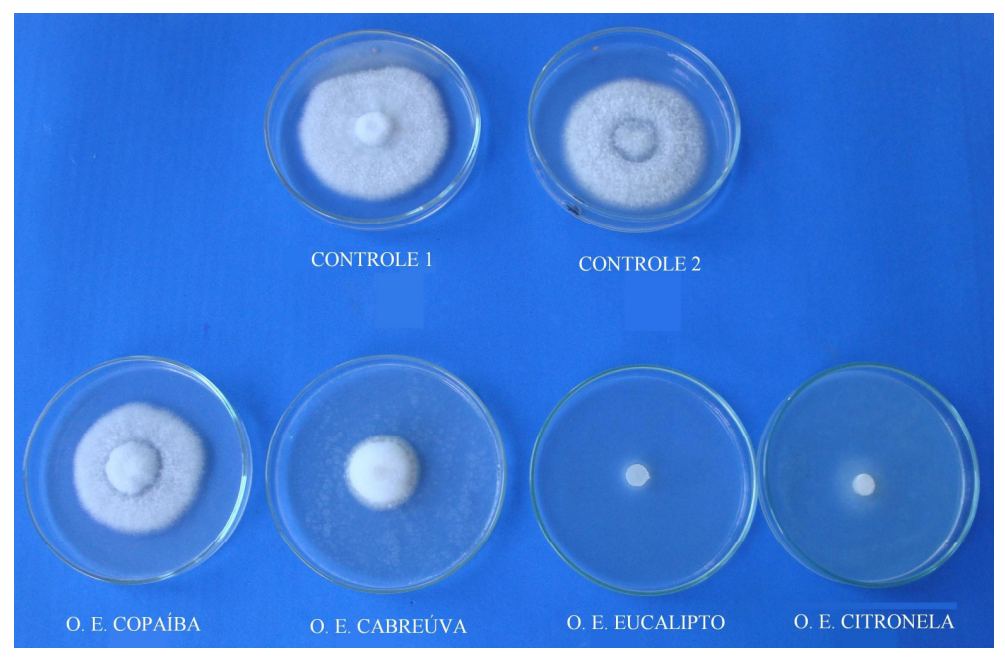

Figura 2: Crescimento micelial in vitro do fungo Colletotrichum gloeosporioides sob ação de óleos essenciais no $5^{\circ}$ dia de incubação. 
Os resultados observados nesse estudo podem ser comparados àqueles obtidos por Aguiar et al (2008), ao estudar os óleos essenciais de Eucalyptus citriodora e Cymbopogon citratus, que observaram $100 \%$ de ação fungitóxica sobre $C$. gloeosporioides nas concentrações de $1000 \mu \mathrm{L} / \mathrm{L}$ a $1500 \mu \mathrm{L} / \mathrm{L}$ e de $61 \%$ na concentração de $1500 \mu \mathrm{L} / \mathrm{L}$, respectivamente.

Marques et al (2003) avaliou os efeitos in vitro e in vivo do monoterpeno citral e do óleo essencial de C. citratus no controle do fungo C. gloeosporioides. No experimento in vitro, citral diluído a $60 \%$ (v/v) e o óleo essencial de C. citratus a $50 \%$ (v/v) inibiram totalmente o crescimento micelial do patógeno. Nos resultados in vivo o citral a $1,0 \%$ inibiu em $38,3 \%$ o crescimento de C. gloeosporioides nos frutos. Na concentração de $1,5 \%(\mathrm{v} / \mathrm{v})$, este monoterpeno proporcionou redução mais significativa, resultando numa inibição de $61,1 \%$. O óleo de C. citratus a 1,0 e 1,5 \% inibiu em 18,6 e 19,9\%, respectivamente.

Ao avaliarem o efeito dos óleos essenciais de Cymbopogon citratus, Eucalyptus citriodora, Mentha arvensis e Artemisia dracunculus no controle de C. gloeosporioides, Carnelossi et al (2009) obtiveram como resultado a inibição de $100 \%$ do crescimento micelial do fungo para todos os óleos testados, na alíquota de $50 \mu \mathrm{L}$. O óleo de C. citratus foi o mais eficiente, pois causou inibição de $100 \%$ a partir da alíquota de $10 \mu \mathrm{L}$.

A avaliação da curva dose-resposta para o óleo de citronela indicou ajuste quadrático com coeficiente de determinação de $82 \%$ entre o crescimento micelial e as concentrações do óleo de citronela (Figura 3). A concentração que apresentou maior inibição do crescimento micelial foi a de $100 \%(\mathrm{p} / \mathrm{v})$ $(\mathrm{P}<0,05)$ em que o halo corresponde a $1 \mathrm{~cm}$, ou seja, não houve crescimento do micélio.

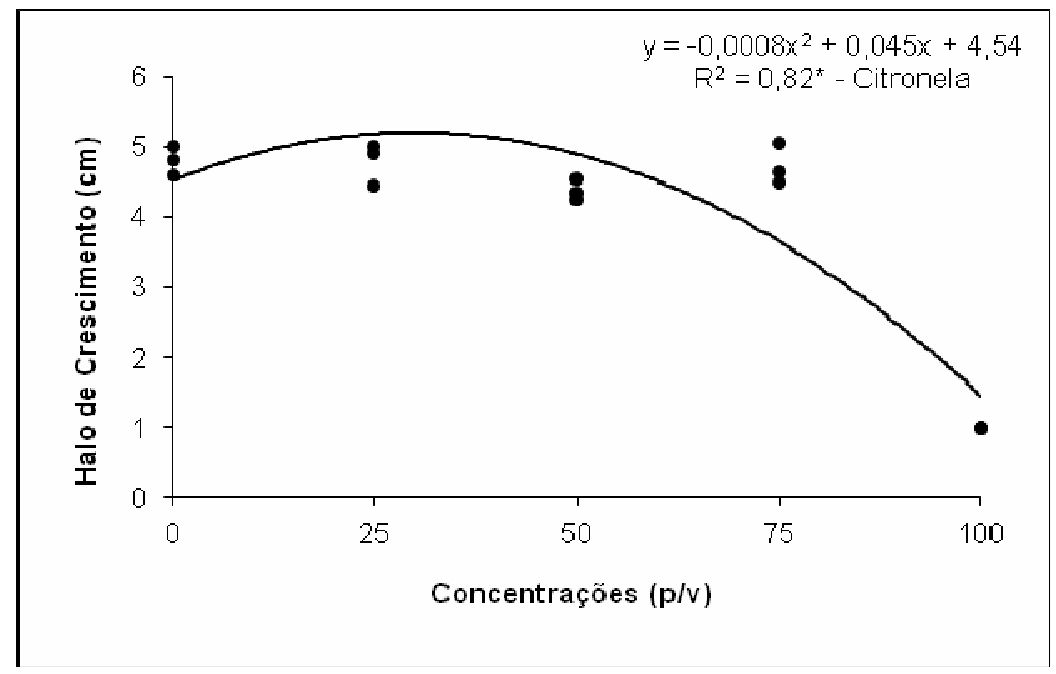

Figura 3: Curva dose-resposta da ação de diferentes concentrações do óleo essencial de citronela sobre o crescimento micelial de Colletotrichum gloeosporioides no $5^{\circ}$ dia de incubação.

Souza Júnior et al (2009) ao analisarem os óleos essenciais extraídos das plantas Lippia sidoides, Ocimum gratissimum, Lippia citriodora, Cymbopogon citratus e Psidium guayava var. pomifera observaram que a partir da concentração de $1 \mu \mathrm{L} / \mathrm{mL}$, os óleos essenciais de todas as espécies vegetais tiveram efeito sobre a germinação dos conídios, com inibição de $100 \%$. As espécies L. sidoides, O. gratissimum, $L$. citriodora e C. citratus inibiram em $100 \%$ o crescimento micelial do fungo. O óleo da $P$. guayava var. pomifera mostrou inibição crescente sobre o micélio do $C$. gloeosporioides com o aumento das concentrações desse óleo.

O óleo essencial de citronela (Cymbopogon citratus), segundo Nascimento (2007), tem como componente principal o citronelal (42,75\%) e em menor quantidade o geraniol (36\%). Quintas Júnior et al (2008) (apud BARBOSA, 2011) analisaram a composição do óleo essencial de Cymbopogon winterianus e encontraram como componentes majoritários: geraniol $(40 \%)$, citronelal $(27,44 \%)$, citronelol $(10,45 \%)$ e geranial (8,05\%). Resultados de cromatografia gasosa e espectrômetro de massa mostraram no óleo essencial 
de Cymbopogon nardus: citronelal (36,6\%), geraniol (25,5\%) e citronelol (13,10\%) (OOTANI, 2010). As espécies dessa família detêm uma vasta gama de constituintes químicos, ao passo que vários desses compostos são aproveitados na indústria de alimentos, amido, açúcar e óleos essenciais (BARBOSA, 2011). O óleo essencial de citronela é utilizado na fabricação de perfumes e cosméticos, sendo um excelente repelente de insetos. Esse óleo possui atividade anti-séptica, fungistática e bactericida (MANN, 1995 apud OOTANI, 2010).

A avaliação da curva dose-resposta para o óleo essencial de eucalipto indicou ajuste quadrático com coeficiente de determinação de $74 \%$ entre o crescimento micelial e as concentrações do óleo (Figura 4). A concentração que apresentou maior inibição do crescimento micelial foi a de $100 \%(\mathrm{p} / \mathrm{v})(\mathrm{P}<0,05)$, em que não houve crescimento do micélio.

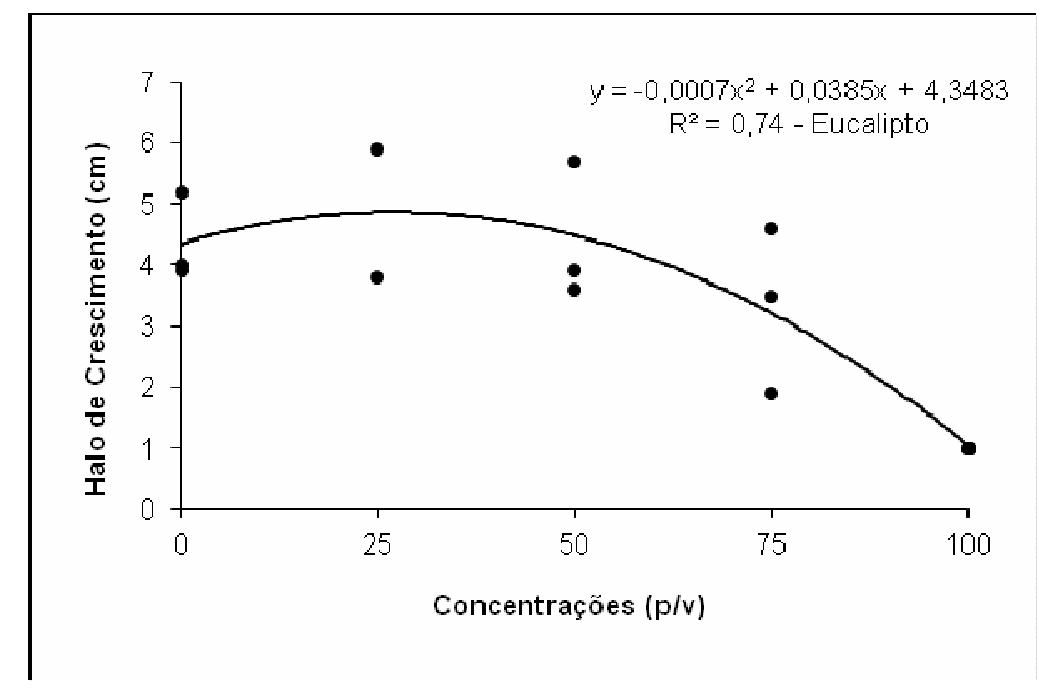

Figura 4: Curva dose-resposta da ação de diferentes concentrações do óleo essencial de eucalipto sobre o crescimento micelial de Colletotrichum gloeosporioides no $5^{\circ}$ dia de incubação.

De acordo com Felix et al (2007), no óleo essencial de Eucalyptus citriodora há compostos com ação antifúngica para tratamento pós-colheita da antracnose do mamoeiro, visto que o óleo inibiu totalmente, tanto o crescimento micelial como a esporulação do patógeno nas concentrações testadas $(1,25 \% ; 2,5 \%$; $3,75 \%$ e $5 \%)$.

A eficiência, in vitro e in vivo, dos óleos de Eucalyptus citriodora e Azadirachta indica no controle de Colletotrichum acutatum em morangueiro foi avaliada por Dias-Arieira et al (2010). In vitro todos os tratamentos apresentaram redução significativa do crescimento micelial do fungo quando comparados ao controle. No campo, apenas o óleo de neem apresentou efeito significativo, reduzindo o abortamento floral e a ocorrência de frutos doentes advindos de flores inoculadas. Porém, maior ocorrência natural de doença foi observada quando a dosagem de $1,0 \%$ foi aplicada semanalmente. Isto sugere a continuidade de nossos trabalhos na avaliação desses óleos que, embora sejam eficientes in vitro contra o fungo testado, nas dosagens utilizadas, devem ser testados in vivo, a fim de confirmar sua eficiência.

Os óleos essenciais de eucalipto são compostos formados por uma complexa mistura de componentes orgânicos voláteis, frequentemente envolvendo de 50 a 100 ou até mais componentes isolados, apresentando grupos químicos como: hidrocarbonetos, alcoóis, aldeídos, cetonas, ácidos e ésteres (BOLAND et al, 1991 apud SALGADO et al, 2003). Estes óleos de eucalipto vêm sendo utilizados como agentes antibacterianos nas pesquisas científicas, apresentando resultados promissores, o que ressalva o seu potencial como agente antimicrobiano, que pode se estender a outros organismos (AHMAD; BEG, 2001 apud SALGADO et al, 2003).

As espécies do gênero Eucalyptus apresentam propriedades aplicadas em diversas áreas, devido as suas conhecidas atividades terapêuticas, fungicida, antibacteriana, anticépticas, adstringente, 
antiinflamatória, cicatrizante e desinfetante. Desta forma, o óleo essencial de eucalipto se apresenta como uma ótima alternativa de fungicida natural, pois existem outros relatos, além deste, de sua eficiência sobre algumas espécies de fungos (VILELA, 2007; OLIVEIRA et al, 2008)

Apesar dos mecanismos de ação dos óleos essenciais estarem pouco caracterizados, parecem estar associados ao caráter lipofílico dos compostos, havendo um acúmulo em membranas, ocasionando perda de energia pelas células microbianas (KNAAK; FIUZA, 2010). A atividade antimicrobiana tem sido atribuída a pequenos terpenóides e compostos fenólicos como timol, carvona, carvacrol, mentol e muroleno, que também na forma pura exibem atividade antifúngica (CONNER, 1993; SMID et al, 1996 apud KNAAK; FIUZA, 2010) Além de não apresentarem riscos de intoxicação para o homem e para o meio, nas condições a serem usadas, os óleos essenciais constituem-se em produto de baixo impacto ambiental.

\section{CONCLUSÃO}

Os óleos essenciais estudados podem ser utilizados no desenvolvimento de métodos alternativos de controle da antracnose em frutos de mamão, com destaque para os óleos de citronela e eucalipto. O óleo de citronela apresentou maior eficiência contra o crescimento micelial de Colletotrichum gloeosporioides in vitro.

Os estudos dos óleos essenciais de citronela e eucalipto são promissores no controle de doenças de plantas e devem ser avaliados sobre sob a ótica do efeito de seus componentes majoritários frente a $C$. gloeosporioides.

Embora os óleos de citronela e eucalipto tenham expressado efeito no controle do fungo em laboratório, experimentos com esses óleos devem ser encorajados in vivo, para se avaliar e comparar sua eficiência em relação aos produtos convencionais utilizados no controle dessa doença.

\section{REFERÊNCIAS}

AGROFIT - Sistema de agrotóxicos fitossanitários. Agrotóxicos. Ministério da Agricultura. http://www.agricultura.gov.br/vegetal/agrotóxicos. Accessed 13 March 2012.

AGUIAR, L. G. de; PEREIRA, A. J.; VIVAS, M.; SILVEIRA, S. F. da; MORAIS, W. B.; JESUS JUNIOR, W. C. de; SILVA, D. G. da. Inibição in vitro do crescimento micelial de Colletotrichum gloeosporioides, por óleo essencial de Eucalyptus citriodora e Cymbopogon citratus. In: XII Encontro Latino Americano de Iniciação Científica. Anais... São José dos Campos, São Paulo, 2008. Disponível em: $<$ http://www.inicepg.univap.br/cd/INIC_2008/anais/arquivosINIC/INIC0534_04_A.pdf $>$ Acesso em: 12 de jan. 2012.

BARBOSA, D. B. M. Estudo da atividade antifúngica da associação do óleo essencial de Cymbopogon winteriaus Jowitt (citronela) com antifúngicos sintéticos sobre espécies de Aspergillus. Tese de doutorado - Odontologia. João Pessoa: Universidade Federal da Paraíba, 2011. Disponível em: $<$ http://bdtd.biblioteca.ufpb.br/tde_arquivos/27/TDE-2011-09-06T073315Z-1160/Publico/arquivototal.pdf $>$ Acesso em: 11 fev. 2012.

BASSETO, E. Quantificação de danos ao longo da cadeia produtiva de pêssegos e avaliação de métodos alternativos de controle de doenças pós-colheita. Tese de doutorado - Agronomia. Piracicaba: Universidade de São 2006.2 Disponível em: <www.teses.usp.br/teses/disponiveis/11/11135/.../ElianeBassetto.pdf> Acesso em 10 jan. 2012.

BENATO, E. A. Controle de doenças pós-colheita em frutos tropicais. Summa Phytopathologica. n. 25, p.90-93, 1999.

BONETT, L. P.; ALMEIDA, M.; GONÇALVES, R. G. A.; AQUINO, T. F. de; BERNARDI-WENZEL, J. Caracterização morfocultural e infecção cruzada de Colletotrichum gloeosporioides agente causal da 
antracnose em frutas e hortaliças em pós.colheita. Ambiência, v.6, n.3, p.451-463, 2010. Disponível em: $<$ www.sumarios.org/sites/default/files/pdfs/623-5440-2-pb.pdf> Acesso em: 20 jan. 2012.

CARDOSO, M. G.; SHAN, A. Y. K. V.; PINTO, J. E. B. P.; DELÚ-FILHO, N.; BERTOLUCCI, S. K. V. Metabólitos secundários vegetais: visão geral, química e medicinal. Lavras: UFLA, 2001. 81 p. (Textos acadêmicos).

CARNELOSSI, P. R.; SCHWAN-ESTRADA, K. R. F.; CRUZ, M. E. S.; ITAKO, A. T.; MESQUINI, R. M. Óleos essenciais no controle pós-colheita de Colletotrichum gloeosporioides em mamão. Rev. Bras. PI. Med., v.11, n.4, Botucatu, 2009, p.399-406. Disponível em: $<$ http://www.scielo.br/pdf/rbpm/v11n4/a07v1 ln4.pdf > Acesso em 20 fev. 2012.

CASTEllani, A. The water cultivation of pathogenic fungi. Ann. Soc. belge Méd. Trop, v.44, n.2, p.217220, 1964. Disponível em: <lib.itg.be/open/asbmt/1964/1964asbm0217.pdf> Acesso em: 02 nov. 2011.

CRAVEIRO, A. A.; MACHADO, M. L. L. De aromas, insetos e plantas. Ciência Hoje, n.4, p.54-63, 1986. Disponível em: <http://dc128.4shared.com/doc/KWIef971/preview.html> Acesso em 25 mar. 2012.

DANTAS, S. A. F.; OLIVEIRA, S. M. A.; MICHEREFF, S. J.; NASCIMENTO, L. C.; GURGEL, L. M. S.; PESSOA, W. L. R. S. Doenças fúngicas pós-colheita em mamões e laranjas comercializados na Central de Abastecimento do Recife. Fitopatol. bras. n.28 v.5, p.528 - 533, set - out, 2003. Disponível em: $<$ www.scielo.br/pdf/fb/v28n5/17667.pdf > Acesso em 18 nov. 2011.

DHINGRA, O.D.; SINCLAIR, J.B. Basic plant pathology methods. Lewis Publishers, Boca Raton. 1995.

DIAS-ARIEIRA, C. R.; FERREIRA, L. da R.; ARIEIRA, J. de O.; MIGUE, E. G.; DONEGA, M. A.; RIBEIRO, R. C. F. Atividade do óleo de Eucalyptus citriodora e Azadirachta indica no controle de Colletotrichum acutatum em morangueiro. Summa Phytopathol., Botucatu, v.36, n.3, p. 228-232, 2010. Disponível em: <http://www.scielo.br/pdf/sp/v36n3/v36n3a07.pdf> Acesso em 10 dez. 2011.

ECKERT, J. W. Post-harvest diseases of citrus fruits. Agriculture Outlook n.54, p.225-232, 1993.

FAO. The State of Food Insecurity in the World. Roma, Itália. p. 1-180, 2009a. Disponível em: $<$ http://apps.fao.org $>$. Acesso em: 15/11/11.

How feed the world in 2050. Roma, Itália. p. 1-35, 2009b. Disponível em: <http://apps.fao.org>. Acesso em: 15/11/11.

FAOSTAT - Agricultural statistics database. Rome. World Agricultural Information Center, versão de 27/10/2009c. Disponível em: <http://apps.fao.org>. Acesso em: 15/11/11.

FELIX, K. C. S.; SILVA, J. C.; CARNAÚBA, J. P.; OliVEIRA, A.; AMORIM, E. P. R. Atividade antifúngica de extratos vegetais e óleos essenciais sobre Glomerella cingulata em frutos de mamão. In: CONGRESSO BRASILEIRO DE DE FITOPATOLOGIA, Maringá. 2007. Anais... Maringá: Gráfica e Editora Clichetec Ltda, ago. 2007. p. 119.

FREIRE, F. das C. O.; CARDOSO, J. E.; VIANA, F. M. P. Doenças de fruteiras tropicais de interesse agroindustrial. Brasília: Embrapa Informação Tecnológica, 2003. 687 p.

GAYET, J. P.; BLEIN, R. Mamão para exportação: procedimentos de colheita e pós-colheita. Brasília. Embrapa-SPI, 1995.

KNAAK, N.; FIUZA, L. M. Potencial dos óleos essenciais de plantas no controle de insetos e microorganismos. Neotropical Biology and Conservation, n.5, v.2, p.120-132, maio-agosto, 2010. 
Dsponível em: <www.unisinos.br/blogs/ppg-biologia/files/.../art08_knaak_et_al.pdf> Acesso em: 21 fev. 2012.

MANICA, I. Fruticultura Tropical. 3 - Mamão. São Paulo: Ceres, 1982. 255p.

MARQUES, S. S.; SANTOS, M. P.; ALVES, E. S. S.; VILCHES, T. T. B.; SANTOS, R. B.; VENTURA, J. A.; FERNANDES, P. M. B. Uso de óleos essenciais no controle de Colletotrichum gloeosporioides, agente causal da antracnose em frutos do mamoeiro. Papaya Brasil, 2003, p. 591-593. Disponível em: <www.fundagres.org.br/downloads/pi.../2003_fitopatologia_05.pdf> Acesso em: 11 nov. 2011.

MARTINS, C. R.; FARIAS, R. de M. Produção de alimentos x desperdício: tipos, causas e como reduzir perdas na produção agrícola - revisão. Revista da FZVA, Uruguaiana, v. 9, n. 1, p. 20-32, 2002. Disponível em: <revistaseletronicas.pucrs.br/ojs/index.php/fzva/article/view/.../1650> Acesso em: 14 dez. 2012.

MORANDIR, M. M. B. Avanços no controle biológico de doenças em pós-colheita. In: Simpósio de Controle de Doenças de Plantas, v. 2, Lavras. Anais... Lavras UFLA, 2002. p. 71-78.

MOURA, R. D. Produtos biológicos e alternativos no controle de doenças pós-colheita em melão cantaloupe. Dissertação de Mestrado - Agronomia. Mossoró, RN: Universidade Federal Rural do Semiárido, 2007. Disponível em: <www.dominiopublico.gov.br/pesquisa/DetalheObraForm.do?...> Acesso em 13 nov. 2011.

NASCIMENTO, P.F.C.; NASCIMENTO, A.C.; RODRIGUES, C.S.; ANTONIOLLI, AR.; SANTOS, P.O.; JÚNIOR A. M. B.; TRINDADE, R.C. Atividade antimicrobiana dos óleos essenciais: uma abordagem multifatorial dos métodos. Revista brasileira Farmacognosia, v.17, p.1, 2007.

OLIVEIRA, C. F. R. Aspectos funcionais e estruturais do inibidor de tripsina de Entada acaciifolia. Dissertação de Mestrado, UNICAMP, Campinas, SP, 102p, 2011.

OliveirA, O. R. DE; TERÃO, D.; CARVAlHO, A. C. P P. de; INNECCO, R.; ALBUQUERQUE, C. C. de. Efeito de óleos essenciais de plantas do gênero Lippia sobre fungos contaminantes encontrados na micropropagação de plantas. Revista Ciência Agronômica, Fortaleza, v.39, n.1, p. 94-100, jan./mar, 2008. Disponível em: <www.alice.cnptia.embrapa.br/handle/doc/160999> Acesso em: 16 mar. 2012.

OOTANI, M. A. Atividade inseticida, antifúngica e herbitóxica dos óleos essenciais de Eucalyptus citriodora e Cymbopogon nardus. Dissertação de mestrado - Produção vegetal. Gurupi: Universidade Federal do Tocantins, 2010.2 Disponível em: $<$ www.uft.edu.br/.../doc/MARCIO\%20AKIO\%200OTANI.pdf $>$ Acesso

PIATI, A.; SCHNEIDER, C. F.; NOZAKI, M. de H. Efeito in vitro do óleo essencial de Eucalyptus globulus sobre o crescimento e desenvolvimento de Penicillium sp. Semina: Ciências Agrárias, Londrina, v. 32, n. 3 , p. 1033-1040, jul/set, 2011. Disponível em: <www.uel.br/revistas/uel/index.php/semagrarias/article/.../8377> Acesso em 14 nov. 2011.

PIMENTEL GOMES, F. Curso de Estatística Experimental. 14a edição. (Ed.). Piracicaba, 2000. 477p.

PRASHAR, A.; HILI, P.; VENESS, R. G.; EVANS, C. S. Antimicrobial action of palmarosa oil (Cymbopogon martinii) on Saccharomyces cerevisae. Phytochemistry, n. 63, p.569-575, 2003. Disponível em: <www.sciencedirect.com/.../S0031942203002267> Acesso em: 14 nov. 2011.

SAEG - Sistema para Análises Estatísticas e Genéticas. Versão 8.0. Universidade Federal de Viçosa UFV. Viçosa, 2000. 
SAlGADO, A. P. S. P.; CARDOSO, M. das G.; SOUZA, P. E. de; SHAN, A. Y. K. V.; PEREIRA, A. de A.; MUNIZ, F. R. Estudo dos constituintes químicos do óleo essencial das folhas de Eucalyptus e sua atividade fungitóxica. Ciênc. agrotec. vol.27, n.2, Lavras, Mar./Apr, 2003.

SANTOS, R. I. Metabolismo Básico e Origem dos Metabólitos Secundários. In: SIMÕES, C. M. O.; SCHENKEL, E. P.; GOSMANN, G.; MELlO, J. C. P.; MENTZ, L. A.; PETROVICK, P. R. Farmacognosia: da planta ao medicamento. 5. ed. Porto Alegre, RS: Ed. da UFSC, 2004. 1102 p.

SENHOR, R. F.; SOUZA, P. A. de; ANDRADE NETO, R. C.; MARACAJÁ, P. B.; NASCIMENTO, F. J. do. Manejo de doenças pós-colheita. Revista Verde (Mossoró - RN - Brasil), v.4, n.1, p. 00 - 13, janeiro/março, 2009. Disponível em: <www.gvaa.com.br/revista/index.php/RVADS/article/view/139/139> Acesso em: 12 nov. 2011.

SILVEIRA, N. S. S.; MICHEREFF, S. J.; SILVA, I. L. do S. S. da; OLIVEIRA, S. M. A. de. Doenças fúngicas pós-colheita em frutas tropicais: patogênese e controle. Caatinga, Mossoró, v.18, n.4, p.283-299, out./dez, 2005. Disaponível em: <www.pgfitopat.ufrpe.br/publicacoes/samirevpos.pdf $>$ Acesso em: 12 nov. 2011.

SIMÕES, C. M. O.; SCHENKEL, E. P.; GOSMANN, G.; MELlO, J. C. P.; MENTZ, L. A.; PETROVICK, P. R. Farmacognosia: da planta ao medicamento. 5. ed. Porto Alegre, RS: Ed. da UFSC, 2004. 1102 p.

STANGARLIN, J. R.; SCHWAN-ESTRADA, K. R. F.; CRUZ, M. E. S.; NOZAKI, M. H. Plantas Medicinais e controle alternativo de fitopatógenos. Biotecnologia Ciência e Desenvolvimento, n.11, p.1621, 1999. Disponível em: <www.biotecnologia.com.br/revista/bio11/plantas.pdf> Acesso em: 23 mar. 2012.

STEVENS, C. et al. Ultraviolet light induced resistance against postharvest diseases in vegetables and fruits. In: WILSON, C.; CHALUTZ, E. (Ed.). Biological control of postharvest diseases of fruits and vegetables. Washington, DC: U.S. Department of Agriculture, 1991. p.268-290.

SOUZA JÚNIOR, I. T.; SALES, N. L. P.; MARTINS, E. R. Efeito fungitóxico de óleos essenciais sobre Colletotrichum gloeosporioides, isolado do maracujazeiro amarelo. Revista Biotemas, n.22, v.3, setembro, 2009. Disponível em: <www.biotemas.ufsc.br/volumes/pdf/volume223/77a83.pdf> Acesso em: 20 nov. 2011.

VILELA, G. Efeito do óleo essencial de Eucalyptus globulus sobre espécies produtoras de aflotoxinas. Dissertação (Mestrado em Ciências) - Escola Superior de Agricultura Luiz de Queiroz, Piracicaba, 2007. Disponível em: <www.teses.usp.br/teses/disponiveis/11/11141/.../GeorgiaVilela.pdf> Acesso em: 22 mar. 2012. 